\title{
Grounding theories of powers
}

\author{
Matthew Tugby ${ }^{1}$ (D) \\ Received: 5 November 2019 / Accepted: 6 July 2020 / Published online: 22 July 2020 \\ (c) The Author(s) 2020
}

\begin{abstract}
Necessitarianism, as we shall use the term, is the view that natural properties and causal powers are necessarily connected in some way. In recent decades the most popular forms of necessitarianism have been the anti-Humean powers-based theories of properties, such as dispositional essentialism and the identity theory. These versions of necessitarianism have come under fire in recent years and I believe it is time for necessitarians to develop a new approach. In this paper I identify unexplored ways of positing metaphysically necessary connections in nature, using the concepts of grounding and essential dependence. For example, I show that one could be a necessitarian by insisting that the properties of things necessarily ground their powers, and that one can maintain this while rejecting dispositional essentialism. Using different combinations of claims about grounding and essential dependence (or lack thereof), I map out a spectrum of new positions and compare them to previous theories of natural modality. Some of these positions are compatible with Humean metaphysics (given certain readings of Hume's Dictum) while others are not. The overall aim of the paper is to provide a new metaphysical framework for understanding theories of powers and thereby launch a new necessitarian research programme.
\end{abstract}

Keywords Natural modality $\cdot$ Causal powers · Necessity $\cdot$ Grounding $\cdot$ Dependence

\section{Contemporary necessitarianism: dispositional essentialism and the identity theory}

Necessitarianism, as we shall use the term, is the view that there are metaphysically necessary connections of some sort between a thing's natural properties and its pow-

Matthew Tugby

matthew.tugby@durham.ac.uk

1 Durham University, Durham, UK 
ers. ${ }^{1}$ Natural properties are the qualities of (or relations between) things. Properties determine how things are. Powers, as we shall understand them, concern the natural modal profile of a thing: to say that a thing has a certain power is to say, roughly, that it can, or would, or must behave in a certain way in certain circumstances. An example of a natural property is that of having unit negative charge and an example of a power associated with this property is the disposition to repel other negatively charged things. ${ }^{2}$ Necessitarians say that this property metaphysically necessitates this power. ${ }^{3}$ In contrast, opponents of necessitarianism, such as Lewis (2009) and Armstrong (1983), insist that the connection is metaphysically contingent. ${ }^{4}$

There are many reasons to be attracted to necessitarianism. For example, it can provide one with a straightforward answer to the question of why the world exhibits behavioural order. The answer is that the properties of things necessarily constrain the powers of those things (or the propensities of things, if the world is not deterministic), which means that the world's inhabitants cannot fail to behave in fairly predictable ways..$^{5}$ This, in turn, promises to provide firm foundations for our predictive practices in science. Another benefit of necessitarianism is that it avoids what many take to be counterintuitive modal consequences of Humean contingentism, such as the possibility of mass and charge swapping their nomic/causal roles in other possible worlds (see e.g. Black 2000; Bird 2007, Ch. 4; Mumford 2004, Ch. 6).

There are different theories about the precise nature of the modality associated with powers/dispositions. For example, some argue that powers are best characterized in terms of subjunctives (e.g. Bird 2007, Ch. 3), while Vetter (2014) argues that dispositions concern graded 'can' possibilities. ${ }^{6}$ Some flesh out the notion of powers using

\footnotetext{
${ }^{1}$ This version of necessitarianism is closely related to what Bird calls 'weak necessitarianism' (Bird 2007, pp. 49-50). It is weak in the sense that it does not entail that the same laws of nature hold in all possible worlds: the laws must only hold in the worlds in which the properties in question exist. Thus, weak necessitarianism is compatible with the possibility of so-called alien properties, which may give rise to powers and laws that are radically different from those in the actual world. Hence, necessitarianism in my sense should not be confused with other versions of necessitarianism (such as Wilson's modal necessitarianism, 2013) on which the laws of nature are the same in all possible worlds.

2 For the purposes of this paper I shall use the terms 'powers' and 'dispositions' interchangeably.

${ }^{3}$ Note that this necessity claim is distinct from the claim that powers causally necessitate their manifestations once triggered. That is, necessitarians in my sense can disagree on whether powers causally necessitate their manifestations. For example, Ellis (2001) is a powers theorist who accepts that powers necessitate their manifestations, while Schrenk (2010) and Mumford and Anjum (2011) argue that powers do not necessitate
} their manifestations.

${ }^{4}$ Note also that this contingency claim is compatible with the idea that the connection is naturally or physically necessary, since these forms of necessity are weaker than metaphysical necessity. For example, Armstrong's 'nomological necessitation' theory of laws (1983) allows that the properties in our world might confer different powers in other possible worlds, in virtue of different laws of nature obtaining at those worlds. Hence, Armstrong is not a necessitarian in my sense.

5 Armstrong (1983) claims that his nomological necessitation theory brings similar benefits, but as we shall see later, necessitarians usually try to leave us with a more parsimonious ontology (and ideology) than Armstrong's. Moreover, many necessitarians think that the governing conception of laws is unworkable (see e.g. Bird 2007, Ch. 4; Mumford 2004, Ch. 6).

6 To be clear, the claim here is not that powers or dispositions are reductively analysable in terms of, say, subjunctives or graded possibilities. There are reasons to be sceptical about this reductive project (see e.g. Martin 1994). Nonetheless, few philosophers would deny that there is an extremely close connection between power ascriptions and certain kinds of modal ascription. Bird (2007, p. 43), for example, is happy 
causal language (e.g. Shoemaker 1980) or nomic language (e.g. Swoyer 1982; Yates 2013, Sect. 5.3), while others associate powers with a primitive form of dispositional modality (Mumford and Anjum 2011). For the purposes of this paper, we shall remain flexible about the precise nature of power modality. There are also many different theories about the metaphysical status of properties. Some claim that properties form a fundamental ontological category and view them as universals or (sets of) tropes. Others accept that properties exist but do not take them to be fundamental, providing instead 'nominalist' analyses using concepts such as set membership. Again, for the purposes of this paper we shall remain neutral about the precise nature of properties. One of the reasons for being flexible on these matters is that although most versions of necessitarianism are in the property realist camp, some are conducive to certain forms of nominalism. As we shall see, some of the theories to be explored are also compatible with aspects of Humeanism, depending on how one formulates Hume's Dictum. The main aim of this paper, though, is to set out a new conceptual framework for necessitarianism rather than to commit to a particular version of it.

A crucial question that all necessitarians face is this: what is the source of the metaphysically necessary connections between properties and powers? One of the reasons why this question is pressing, and arguably why contingentist theories have been so popular, is that many find the alleged necessary connections between properties and powers to be opaque. For example, as Armstrong explains, 'in trying to discover the laws of nature, scientists feel free to consider possibilities in a very wide-ranging manner, quite unlike the constraints which naturally suggest themselves in logical and mathematical argument' (1983, p. 158). What Armstrong is getting at here is that it does not seem difficult to conceive of the properties instantiated in our world behaving in completely different ways.

In recent decades, the main strategy that necessitarians have employed to deal with the Armstrongian worry relies heavily on certain claims about the essences or identities of properties. However, there are reasons for thinking that these necessitarian strategies have not been successful. The strategy has led to a relatively narrow conception of necessitarianism and led to views such as dispositional essentialism and the identity theory of properties, which as we shall see face serious objections. My aim in this paper is to open up new options for the necessitarians, ones which are based on notions of metaphysical grounding and essential dependence-relations that plausibly involve metaphysically necessary connections.

The orthodox necessitarian strategy for powers theorists mirrors that found in Kripke's work in Naming and Necessity (1980) on natural kinds. One of Kripke's achievements was to persuade many people that there is a distinctive metaphysical form of necessity that is different from logical necessity, such as the necessity that water is $\mathrm{H}_{2} \mathrm{O}$ or that gold is the element with atomic number 79. Importantly, the source of these metaphysical necessities is the essences or identities of things. Why is it necessary that $\mathrm{H}_{2} \mathrm{O}$ is water? A Kripkean answer is that $\mathrm{H}_{2} \mathrm{O}$ is identical with water. Why is it necessary that gold has an atomic number of 79? A Kripkean answer is that this atomic number is an essential property of gold. Kripke himself said little

Footnote 6 continued

to accept that there is a 'necessary biconditional equivalence' between power ascriptions and subjunctive conditionals of a certain kind, even though he is sceptical of reductive analyses of dispositions. 
about cases involving natural properties and powers. However, it is not difficult to see how the Kripkean strategy can be carried over to the case of powers by necessitarians. Why is it necessary that mass confers gravitational powers of a certain sort? A necessitarian answer: the property of mass is identical with those gravitational powers; or if identity is too strong then such powers are at least part of the essence of the mass property. Prominent advocates of the identity theory of properties, often referred to as the 'powerful qualities' view, include Carruth (2016), Engelhard (2010), Heil (2003), Ingthorrson (2013), Jacobs (2011), Jaworski (2016), Martin (2008), Schroer (2010), Strawson (2008) and Taylor (2013). ${ }^{7}$ Prominent examples of power (or 'dispositional') essentialists about properties include Alvarado (forthcoming), Bird (2007), Dumsday (2013), Ellis (2001), Ellis and Lierse (1994), Oderberg (2017), Shoemaker (1998), Swoyer (1982) and Yates (2013). There are also many necessitarians who tend not to use essentialist language but who nonetheless agree that some natural properties are individuated, at least in part, by the powers that they confer (e.g. Cartwright 1989; Chakravartty 2007; Fales 1990; Harré and Madden 1975; Kistler 2002; Marmodoro 2017; Maxwell 1968; McKitrick 2018; Molnar 2003; Mumford 2004; Vetter 2015; Whittle 2008; Williams 2019). Such philosophers therefore count as dispositional essentialists as we are using the term. ${ }^{8}$

In the next section I shall briefly rehearse some of the common objections facing dispositional essentialism and the identity theory of properties. For the purposes of the discussion I shall assume that the identity theory of properties and dispositional essentialism are distinct views, since (for example) dispositional essentialists like Bird (2007) reject Heil's identity theory (2003). In a recent paper, Taylor (2018) argues that on close inspection the theories of Bird and Heil are difficult to distinguish, but examining this issue in detail would distract us from the main business of the paper. ${ }^{9}$ I shall also not consider potential responses to the objections discussed in the next section, since they have been discussed in detail elsewhere (see e.g. Barker 2013; Jaag 2014). To repeat, the main purpose of the paper is to open up conceptual space for new fruitful work on necessitarianism using the contemporary notions of grounding and essential dependence. We shall begin this task in Sect. 3. Even if one does not think that the identity and dispositional essentialist theories are as problematic as I do, I hope that one will see the value of exploring new versions of necessitarianism against which the merits of other theories of natural modality can be compared.

\footnotetext{
7 This identity view is not to be confused with the identity theory about dispositions, held by Armstrong (1973; see also Lewis 1997). Armstrong's theory is sometimes described as the view that dispositions are (contingently) identical with their categorical causal bases. However, strictly speaking, on Armstrong's theory dispositions are also constituted by the nomic relations in which categorical properties stand.

${ }^{8}$ Care is needed, though, because 'dispositional essentialism' is a slippery term. In this paper I take dispositional essentialism to be a thesis about the nature of natural properties, such as mass and charge. However, Ellis and Lierse (1994), who were among the first to use the term 'dispositional essentialism' take the further essentialist step of claiming that natural kinds have essential dispositional properties (see also Dumsday 2013). For the purposes of this paper we need not discuss this further debate about natural kinds, since dispositional essentialism about properties is sufficient for a necessitarian powers theory.

9 I note, though, that given I think the identity theory is problematic, it wouldn't make any difference (as far as this paper is concerned) if some versions of dispositional essentialism collapse into the identity theory.
} 


\section{Familiar problems facing dispositional essentialism and the identity theory}

Let us start with dispositional essentialism, the view that natural property types have a dispositional essence - an essence that is modal and relational. As mentioned earlier, there is disagreement about the precise nature of this modality but perhaps the most widely held view is that dispositional essences should be fleshed out in terms of subjunctive conditionals (e.g. Bird 2007, Ch. 3). Another important feature of dispositional essentialism is that its advocates are strong actualists about modality, which means they wish to ground modal talk in the properties of concrete objects rather than, say, possible worlds (e.g. Vetter 2015). The most detailed articulation of contemporary dispositional essentialism is to be found in the work of Bird (2007), which builds on work by Ellis (2001) and Mumford (2004).

In recent years, the most common complaint raised against Bird-type dispositional essentialism is that it harbours a structural problem. This worry has been raised by Barker (2013) and articulated in detail by Jaag (2014). Roughly, the worry is that it is difficult to see how the properties of objects could both ground modal facts about those objects and at the same time be essentially dependent on those facts. Prominent philosophers in the literature on essence have been sceptical of the idea that anything could ground that on which it essentially depends (see e.g. Jaag 2014, Sect. 3; Fine 2015, p. 297). If the properties of things ground facts about natural modality (such as subjunctive facts), then those modal facts are plausibly derivative entities. Indeed, one of the benefits of dispositional essentialism is precisely supposed to be that it explains away the laws of nature (e.g. Bird 2007, Ch. 9; see also Mumford 2004). But if natural modality is derivative, it is difficult to see how properties-which dispositional essentialists take to be fundamental—could be essentially dependent on natural modality, for this would mean that something fundamental (a property) has an essence which is not itself fundamental (again see Jaag 2014, Sect. 3 for details). If properties have a non-fundamental, derivative essence, then surely the properties will be derivative. But not everything can be derivative!

What options do the dispositional essentialists have? The objection above rests in part on the idea that grounded entities are derivative relative to their grounds- which depends in turn on the asymmetry of grounding (more on this later). One option for the dispositional essentialists is to question this assumption and accept the idea that properties and natural modality might be equally fundamental and stand in a symmetric relationship of ontological dependence. This suggestion is explored by Yates (2018, Sect. 4) and Jaag (2014, pp. 12-13), but the notion of symmetric ontological dependence remains controversial. Another option is to reverse the grounding claim and maintain that facts of natural modality ground the properties of things rather than vice versa. This view would be consistent with the claim that properties have a dispositional essence. We shall discuss this option more in Sect. 6. However, for current purposes we should note that this theory comes at the cost of making properties nonfundamental. Such a view would therefore not be attractive for those who hold that universals or tropes form a fundamental ontological category-which includes most (if not all) dispositional essentialists. Moreover, it is far from clear that such a view can 
provide an illuminating account of modality, since natural modal facts end up being primitive.

For these reasons, one might be tempted by the identity theory of properties, on which properties are said to be powerful qualities. I take it that this is a distinct and simpler theory than Bird-type dispositional essentialism. Identity theorists tend not to flesh out powers in subjunctive or relational terms, as Bird does, and identity theorists such as Heil and Martin tend to avoid the terminology of essence altogether. Moreover, Heil and Martin accept that properties are qualitative, a claim that Bird and his followers typically resist. According to the identity view, properties and powers are equally fundamental: properties are at once qualitative and modal. Heil summarises the view as follows (2003, p. 111):

Identity: a property $\mathrm{P}$ 's dispositionality, $\mathrm{Pd}$, is $\mathrm{P}$ 's qualitativity, $\mathrm{Pq}$, and each of these is $\mathrm{P}: \mathrm{Pd}=\mathrm{Pq}=\mathrm{P}$

Unfortunately, for all its benefits the identity theory faces some fundamental objections - objections that are distinct from Jaag's criticisms of dispositional essentialism. The main challenge is that many find it difficult to see how qualitative properties and powers can be identical. Qualitative properties and powers appear to have different features, which suggests they are non-identical (see e.g. Barker 2013, p. 649; Williams 2019, pp. 115-116). Armstrong, for example, takes an incredulous tone when he says that qualities and powers 'are just different, that's all' (2005, p. 315) and that if one is going to identify qualities and powers, one might 'as well identify a raven with a writing desk' (Armstrong 2004, p. 141). What, though, are the specific reasons for thinking that qualitative properties and powers are distinct? As Taylor (2018) has pointed out, some of the reasons given in the literature are bad reasons because they beg the question against the identity theory. For instance, in places Armstrong defines qualities (or what he calls 'categorical' properties) precisely as non-dispositional properties (1997, p. 69), which of course makes the identity theory sound contradictory. But this will not worry the identity theorists, because their view is precisely that qualitative properties are dispositional.

A better version of the Armstrongian complaint is one that focuses on the ways in which different qualities and different powers are distinguished. Even if powers are essentially tied to qualities in some way, power types are typically identified and distinguished in relational terms, by the manifestations that they are powers for (see e.g. Bird 2007; Lowe 2010). For instance, to know what the power of fragility is just is to know that fragility is the power to break. Indeed, even Heil, himself an identity theorist, concedes that powers are identified relationally because it is this fact that generates an alleged regress problem facing Bird's version of dispositional essentialism (Heil 2003, Ch. 10). In contrast, it seems that qualities have a self-contained, non-modal essence; an intrinsic suchness. We can understand what, say, the quality of sphericality is without reference to anything else. Qualities are self-individuating, one might say.

Ingthorrson (2013) has offered one of the most detailed responses to the worry just outlined, and his response is that these different modes of identification of qualities and powers merely reflect an epistemological or conceptual difference, rather than a metaphysical difference. On his view, the best thing for an identity theorist to say is that we can single out a property in thought in one of two ways: either directly, as when we, say, directly perceive a shape, or indirectly via the effects that the property 
instance produces in other things. When we single out a property in the former way, we identify it qualitatively, but when we use the latter method we identify it powerfully.

I agree that Ingthorsson's response is a natural route for the identity theorist to take but the problem is that the theory then becomes more about epistemology than metaphysics, which compromises its status as thoroughgoing necessitarianism. Of course, the metaphysical thesis that properties are at once qualitative and dispositional can be consistently held alongside the epistemic point that there are qualitative and dispositional ways of conceptualising or picking out those properties. However, if one tries to demystify the identity claim by understanding it in the way that Ingthorrson does, as an epistemological claim, then the theory ends up saying little about the underlying metaphysical nature of properties. As Molnar complains (2003, p. 154), this makes it difficult to see how the identity theory differs in a significant way from a view that Mumford (1998) called 'neutral monism' ${ }^{10}$ Such a theory is more about modes of presenting properties and is metaphysically neutral about the nature of properties themselves. It is therefore difficult to see on what basis a neutral monist can say that there are metaphysically necessary connections between the qualitative and dispositional aspects of properties.

Now that we have briefly considered problems with orthodox forms of necessitarianism-the dispositional essentialist and identity theories-let us begin to explore some different options.

\section{Necessitarianism with grounding}

Rather than being underpinned by property identities or property essences, necessary connections can be underpinned instead by relations of grounding. To say that $\mathrm{X}$ grounds $\mathrm{Y}$ is to say that $\mathrm{Y}$ exists in virtue of $\mathrm{X}$. Grounding is a metaphysical determination relation that provides an explanation for why something is so. We shall take it that, first and foremost, grounding is a relation between entities in the world. ${ }^{11}$ A common example of grounding is that the existence of a set is grounded in the existence of its members. Importantly for our purposes, the orthodox view of grounding is that if $\mathrm{X}$ fully grounds $\mathrm{Y}$, then it is metaphysically necessary that $\mathrm{Y}$ exists if $\mathrm{X}$ does. Among those who favour this necessitarian view of grounding are Audi (2012a), Dasgupta (2014), deRosset (2010), Fine (2015), Rosen (2010) and Trogdon (2013). The main reason for accepting grounding necessitarianism is that full grounds are supposed to fully determine and metaphysically explain that which they ground. But if the relationship between grounded entities and their full grounds is contingent, it is difficult to see how those grounds can provide a complete metaphysical explanation for that which they ground. ${ }^{12}$ For the purposes of this paper, I shall assume this orthodox

\footnotetext{
10 This sort of worry has also been raised by Jacobs (2011, p. 89).

11 I have no objection to those who also speak of true propositions being grounded, as Fine does in his earlier work. However, I take it that grounding structures between propositions obtain because of the grounding structures in concrete reality.

12 As is the case with any philosophical principle, the orthodoxy has been questioned. For example, Skiles (2015) has discussed what he takes to be counterexamples to grounding necessitarianism. Unfortunately, due to space limitations I must deal with Skiles' concerns elsewhere. However, it is worth noting that even
} 
necessaritarian view about full grounding. It follows from this assumption that we could be necessitarians (in the sense defined earlier) by accepting that the properties of things fully ground their powers (or vice versa). ${ }^{13}$

As we shall see in the next section, grounding commitments still leave room for further claims about essential dependence. Different combinations of grounding and essence claims (or lack thereof) yield a spectrum of new necessitarian positions, many of which avoid objections facing the orthodox approaches discussed in the previous section. My aim is not to choose between the theories discussed, though I will raise some preliminary points in favour of the grounding approach developed in this section. In Sect. 5 we shall consider the senses in which the grounding theories are and are not compatible with Humean metaphysics.

So far we have seen how grounding is a metaphysical determination relation that provides an explanation for why something is so. Since that which is grounded depends in some way on its (full) grounds, it is plausible that that which is grounded is less fundamental than its grounds. Hence, grounding relations are said to impose a partial ordering on reality. This ordering is generated by the fact that grounding is plausibly asymmetric, irreflexive, and transitive. Although these formal features have occasionally been questioned in the literature, I shall assume the orthodox view of grounding for the purposes of this paper. ${ }^{14}$ It should be emphasized that to say that grounded entities are derivative is not to say that grounded entities do not exist, as Schaffer emphasizes (2009, Sect. 2). For example, one might flesh out physicalism about the mental as the view that mental properties are grounded in physical properties, but such a view does not imply that mental properties do not really exist; it says only that mental properties exist in virtue of physical properties (see Schaffer 2017 for a detailed development of 'grounding' physicalism). Note also that grounding is not the same thing as entailment. For example, a grounding physicalist can maintain that mental states are grounded in physical states without accepting that physical descriptions entail mental descriptions. And in the current case, a grounding-based necessitarian can accept that qualitative properties ground powers without accepting that qualitative property predications, such as ' $x$ is spherical', entail power predications, such as ' $x$ has the power to roll' (more on this later). Finally, and in line with Audi (2012a, b),

Footnote 12 continued

if Skiles' counterexamples are successful, his criticisms are compatible with the claim that full grounding occurs with metaphysical necessity in some cases. None of his counterexamples involve cases of properties grounding powers (or vice versa).

13 Henceforth, whenever I use the term 'ground' I shall mean 'fully ground' unless otherwise indicated. To be clear, this 'full' notion of grounding is different to the notion of realization that is sometimes employed in the dispositions literature. For example, according to Prior et al. (1982) dispositions are higher-order properties: properties of having first-order properties which play certain causal roles. Higher-order properties are sometimes described as being 'grounded in' first-order properties (e.g. Heil 2012, p. 60). However, on close inspection it is clear that the theory of Prior, Pargetter and Jackson can only involve partial grounding at best. Prior, Pargetter and Jackson hold that the relationship between dispositions and their realizers is contingent and varies with the (contingent) laws of nature (1982, pp. 253-254). Hence, the theory of Prior, Pargetter and Jackson should not be included among the grounding-based theories of necessitarianism discussed in this paper.

14 For example, Rodriguez-Pereyra (2015) argues that grounding is neither transitive, nor irreflexive, nor asymmetric. Thompson (2016) also questions the asymmetry of grounding. As I note in Sect. 8, if some of these formal features turn out to be different then the spectrum of possible positions in Fig. 1 would be larger than that presented here. 
we shall assume that grounded entities are not reducible (in the metaphysical sense) to their grounds. This claim is plausible if one accepts, as I do, that cases of ontological reduction involve identity. As Audi points out (2012b, p. 110), cases of identity cannot involve grounding given the irreflexivity of grounding. ${ }^{15}$ If this is right, then a grounding necessitarian can maintain, as most necessitarians do, that powers are real, irreducible feature of reality.

Is grounding a primitive relation ('Big ' $\mathrm{G}$ ' grounding) or can grounding necessities be realized in different ways by a variety of other metaphysical relations ("small ' $\mathrm{g}$ " relations)? Candidate 'small g' relations include those that hold between parts and wholes, truths and truthmakers, types and tokens, sets and their members, determinates and determinables and so on (see Wilson 2014; Bennett 2017 for further discussion). I lean towards the 'big G' approach but due to space limitations I cannot attempt to settle this debate here. The important assumption for our purposes is that some entities exist in virtue of others and do so as a matter of metaphysical necessity. Fortunately, this is something that "small ' $\mathrm{g}$ " and 'big ' $\mathrm{G}$ "' theorists can agree on. Proponents of either position will, for example, accept that sets exist in virtue of their members and are necessitated by them. For necessitarians who favour a 'small g' approach, one could, for example, appeal to the notion of constitution in order to develop the claim that powers exist in virtue of properties (or vice versa), providing that constitution is not the same thing as identity. The idea then would be that property instantiations are what constitute certain modal facts about objects (or vice versa).

Now, for those seeking a version of necessitarianism based on grounding, a core thesis is as follows:

The grounding theory of powers: For all properties and all powers of things, each power of a thing is fully grounded by some property (or properties) of that thing.

The main difference between this necessitarian theory and the approaches criticized earlier is that an advocate of the grounding theory should reject the claim that the properties of things are identical with, or essentially dependent on, the powers of those things. Grounding is generative and (plausibly) asymmetric, whereas identity is a symmetric and non-generative relation. Hence, as explained earlier, one cannot consistently maintain that the relation between the properties and powers of things is both grounding and identity. Similarly, for reasons already explained, one cannot coherently claim that the properties of things ground the powers of those things while also maintaining that those properties are essentially dependent on the powers. Again, the orthodox view in the grounding literature is that grounded entities are derivative from, which is to say less fundamental than, their grounds. Thus, if properties were essentially dependent on powers, the grounding theorist would have to commit to the bizarre claim that natural properties, which form a fundamental ontological category, have non-fundamental essences (see again Jaag 2014, Sect. 3 for details). The upshot is that if we accept the grounding theory, we must accept that properties have a nondispositional essence.

15 Recall that a grounded entity (call it y) is said to be less metaphysically fundamental than that which grounds it (call it $\mathrm{x}$ ). But if $\mathrm{x}$ is identical with $\mathrm{y}$ then surely $\mathrm{y}$ cannot be less fundamental than $\mathrm{x}$. Rather, if $\mathrm{x}$ is identical with $\mathrm{y}$, then $\mathrm{x}$ and $\mathrm{y}$ are equally fundamental. 
There are, however, at least two ways in which a property can have a nondispositional essence. To borrow terminology from Hildebrand (2016), one option is to say that properties have 'bare quiddities', which is to say that there is nothing more than a bare numerical difference between properties. The other option is to say that properties are have a thick, qualitative nature — a view that Hildebrand calls 'qualitative quidditism' ${ }^{16}$ Hildebrand provides several general arguments for the claim that qualitative quidditism is the most plausible form of quidditism. However, in the context of the grounding theory of powers, there is a specific reason for preferring the qualitative view. If properties are bare and there are no qualitative differences between them, then it would seem a mystery as to why properties necessitate the specific powers that they do, rather than others (see Smith 2016, p. 249, who makes a similar point). In contrast, if properties are qualitative, one can maintain that the powers are constrained by the specific qualitative natures of the relevant properties (more on this below).

This qualitative grounding theory is so simple that it is surprising it has not received more attention in the vast literature on natural modality. This is perhaps because the contemporary notion of grounding has only been developed and refined in recent years. As far as I know, I was one of the first to propose the idea that qualitative properties fully ground powers (Tugby 2012), ${ }^{17}$ but at the time I did not develop the idea in any detail. Jaag (2014, Sect. 4.2) appears to be the first to discuss some of the different grounding theories that are available, but devotes only a few pages to the issue. More recently, Audi (2012b, p. 117), Smith (2016, pp. 250-251), Yates (2018, Sect. 4), Kimpton-Nye (2018, Ch. 3), Azzano (2019, p. 348), Giannotti (2019, pp. 67), Contessa (2019, Sect. 6) and Coates (2020) have discussed specific theories that might qualify as grounding theories in one way or another. However, as far as I know, this is the first paper to offer a detailed systematic analysis of the different grounding and dependence theories that are available.

Before introducing other unexplored versions of necessitarianism, let us offer some further clarifications about the grounding theory before explaining why necessitarians might find it attractive. As mentioned earlier, for the purposes of this paper we may use the terms 'property' and 'power' in a flexible way, which leaves open a variety of ways of developing the grounding theory and should make it attractive to a variety of necessitarians. Most necessitarians are realists about properties in one sense or another. Thus, the properties that ground powers could be, for example, module tropes or modifier tropes (Garcia 2015), or immanent universals or transcendent universals. The grounding claim is compatible with all of these theories of properties as far as

\footnotetext{
16 See also Locke (2012) and Smith (2016) for detailed discussions of the different ways in which quiddities can be characterized.

17 I wrote: 'It is ... purely the qualitative aspects of a thing's properties which ground its dispositions' (2012, p. 278). In that paper I categorized this theory as a version of dispositional essentialism, but for reasons explained in the discussion of Jaag's paper above, I now think that was a mistake. As should be clear in the current paper, the grounding theory of powers and dispositional essentialism provide very different options. In 2012 I briefly fleshed out the grounding claim by appealing to Jacobs' claim (2011) that property instantiations are truthmakers for counterfactuals. There I was assuming that truthmaking is a grounding relation (in line with e.g. Rodriguez-Pereyra 2005; Schaffer 2008). However, it has been argued recently that truthmaking is not a case of grounding (Audi 2019) and in this paper I have avoided fleshing out the notion of grounding in this way.
} 
I can tell. And as we shall see in Sect. 6, there is also a different grounding theory which can be formulated using a nominalist approach to properties.

The question of what we mean by 'power' affects the kind of grounding that is involved in the theory. As we saw above, what is uncontroversial is that powers are modal entities of some sort, since they determine what is naturally possible for an object. But the nature of this modality will affect whether, for example, our notion of grounding is of the flat or dimensioned variety. Grounding theorists draw this distinction to separate cases in which a grounded entity is in the same ontological category as that which grounds it ('flat' grounding) and cases in which a grounded entity is in a different ontological category to that which grounds it ('dimensioned' grounding; see e.g. Schaffer 2009, pp. 375-376). For the purposes of the discussion below I shall for convenience assume that a thing's instantiating a property and a thing's possessing a power are both facts or states of affairs of a certain sort. I shall therefore assume a flat notion of grounding in the case of properties and powers. However, nothing crucial turns on this issue. I accept that the notion of dimensioned grounding is coherent and occurs in many cases, as when Socrates (a concrete entity) grounds the singleton set containing Socrates (an abstract entity). If necessitarians wish to deny that the possession of a power is a fact, and prefer instead a dimensioned theory of grounding, the general theory we are considering would still be available.

Another clarification is that we may remain neutral on whether the necessary correlations between properties and powers are one-to-one. There is no a priori reason why an entity should not ground more than one entity. The grounding theory could, for example, accept that a single property instantiation grounds multiple powers. For this reason, we should not go as far as to suggest that powers are ever fully individuated by the qualitative properties that ground them. ${ }^{18}$ Moreover, we might also want to accept cases in which a single power is collectively grounded in more than one property instantiation, such as a needle's power to pierce linen, which is arguably grounded in the needle's rigidity as well as its shape. Cases of extrinsic dispositions (McKitrick 2003), such as weight, also provide a stock of examples of dispositions that do not depend on a single property instantiation. ${ }^{19}$ Finally, the grounding theory could in principle accept that different kinds of property fully ground the same kind of power, meaning that power types are multiply realizable. Thus, the grounding theory has flexibility in a way that some other versions of necessitarianism, such as the identity theory, does not have.

What, then, are some of the advantages of the grounding theory? I believe there are many but I'll just raise a small number of related points here. As explained, my main aim is to explore the conceptual landscape of necessitarianism rather than to argue for a specific view. What seems clear, though, is that the grounding theory discussed avoids the problems facing the essentialist and identity theories discussed in Sect. 2. Since the grounding theorist need not (and should not) say that properties essentially depend on powers, they avoid the structural problem raised by Jaag in relation to Bird-type dispositional essentialism. And since grounding is not the same thing as

\footnotetext{
18 This would be implausible in any case, for again it is widely accepted that powers are individuated in part by the manifestations that they are powers for (see e.g. Bird 2007; Lowe 2010; Tugby 2013).

19 I am grateful to an anonymous referee for highlighting this point.
} 
identity, it avoids the incoherence worry facing the identity theory. The incoherence worry raised by Barker and others, to recall, is that it is difficult to see how that which fixes the identity of a property can be both non-modal (i.e. qualitative) and modal (i.e. dispositional) (Barker 2013, p. 649). It is clear that the grounding theory avoids this worry, because it can accept that properties and powers are individuated in different ways. According to the grounding theory, qualitative properties are not identical with powers but rather ground powers. On this view, qualitative properties and powers are intimately connected but nonetheless numerically distinct: qualitative properties are fundamental while powers are not.

Perhaps the most obvious advantage is that the grounding theory offers a straightforward actualist theory of natural modality. Actualism is a naturalistic account of modality since it maintains that only the actual world - the one we inhabit-exists. A quick look at the literature on actualism reveals that it is often expressed precisely as a view about the grounding of modality. For example, Vetter finds it natural to describe what she calls 'New Actualism' using the terminology of grounding: 'their shared aim is to identify, within the actual world, the grounds, source, or truthmaker of modal truths' (2011, p. 742). So, if one finds actualism attractive as a general approach to modality, then the view that properties ground natural modality seems an obvious one to pursue. Importantly, as we saw in Sect. 2, if we want to uphold this grounding claim, there are good reasons to reject the dispositional essentialist theory of properties.

Unlike the orthodox versions of necessitarianism, I think that the grounding theory also promises to avoid worries concerning the nature of powers (see Barker 2013 for a range of objections). Importantly, the grounding theory does this while leaving us with all the benefits that necessitarianism brings (see Sect. 1). I suspect that many dispositional essentialists and identity theorists are attracted to their views precisely because they provide a means of being a necessitarian. If that is the case, then I recommend that such theorists convert to the grounding theory. Here is one example of a challenge facing both dispositional essentialists and identity theorists ${ }^{20}$ : Powers are undoubtedly modal entities but it is difficult to see how a modal entity, which concerns not what is the case but what could or would or must be the case, can be part of the furniture of fundamental reality. Indeed, subjunctives with false antecedents are precisely called counterfactuals and it seems almost oxymoronic to say that counterfactuals are fundamental facts which obtain. In my view, this is probably why many have found the idea that powers are both actual and fundamental to be obscure. For example, Psillos (2006, p. 138) complains that on Bird's dispositional essentialist theory of properties, properties have to lead a mysterious 'dual life': on one hand they have to fix how an object constitutively is, while on the other hand they must, as powers, somehow look beyond the object and determine which behavioural manifestations are possible for it. For the same reasons, it could be argued that the identity theory is mysterious, since as we saw earlier it requires the self-same entity to have what looks like two different essences. I think part of the problem here is that powers are being interpreted as entities which are both modal and fundamental. If we really are going to be full-blooded actualists, then a more natural stance is to say that modal facts (in this case powers) are

\footnotetext{
20 There are many others. For example, strong versions of dispositional essentialism face a variety of power regress problems (see e.g. Bird 2007, Ch. 6; Lowe 2010). Given that the grounding theories above take properties to be qualitative, these regress problems are likely to be avoided.
} 
not themselves fundamental but are grounded in concrete entities that are fundamental (in this case qualitative properties).

Of course, the grounding theory sketched here will no doubt face objections, some of which have already been raised on the rare occasions in which grounding necessitarianism has been discussed. For example, Jaag (2014, Sect. 4.2.5) has suggested that versions of dispositionalism based on grounding will face an 'inference problem'. If property descriptions do not entail power descriptions, then why should we accept that qualitative properties ground powers? The link between qualities and powers is opaque, it might be urged. Although it is not my aim to offer a detailed defence of any of the theories discussed in this paper, my suspicion is that there are good lines of response to this sort of objection, one that can draw inspiration from Schaffer's recent work on 'grounding' physicalism (2017). Let me briefly explain.

As Schaffer discusses, physicalism is also criticised on the basis that the link between the physical and the mental is not 'transparent'. For example, it seems that physical descriptions do not entail mental descriptions, which suggests there is a problematic explanatory gap for the physicalists. However, Schaffer argues that this is not a good objection to versions of physicalism on which the physical grounds the mental. This is because even in uncontroversial cases of grounding, the grounding relations are not always 'transparent' is the way that critics of physicalism demand. For example, in cases in which parts compose (ground) wholes, it is not transparent that certain wholes must exist if certain parts do (Schaffer 2017, p. 7).

What conclusions should we draw from this? The answer is that it is rarely (if ever) the case that descriptions of grounds entail descriptions of the grounded, and grounding claims are rarely (if ever) based on claims about such entailments. Rather, grounding is a metaphysical relation that is abductively posited for theoretical reasons in cases where one phenomenon correlates with another. Grounding relations are not somehow deduced from descriptions of the grounds. As explained earlier, the modality of grounding is that of metaphysical necessity. The metaphysical necessity of grounded entities, given the existence of their grounds, is perfectly compatible with the logical or conceptual possibility of grounding entities existing in the absence of grounded entities. This is in part why Schaffer believes that the so-called 'conceivability' objections against physicalism do not stand up against grounding physicalism (2017, pp. 16-18). Importantly, I see no obvious reasons why grounding theorists about powers should not be able to make analogous moves against analogous objections.

In response, opponents might still complain that it is an act of faith to suppose that there is a relation of grounding between properties and powers. Grounding, to recall, is supposed to be a determination relation that underpins metaphysical explanation. But what reasons are there for thinking that properties-considered as non-modal entities - are eligible for explaining modal entities like powers? Or to put the worry in another way, what grounds the fact that properties ground powers? In the absence of such reasons the grounding relation begins to look mysterious, in which case perhaps a necessitarian would be better off accepting that the necessary connections between properties and powers are brute. ${ }^{21}$

21 This is a position that Barker calls 'brute modalism' (2013, p. 611). 
In response, I note firstly that in various historical periods of philosophy there has been considerable support for the idea that modal features necessarily flow from entities whose constitutive essence is non-modal. For example, according to Aquinas's hylemorphism, the soul has a non-dispositional essence but nonetheless necessarily causes various powers (see e.g. Wippel 2000, pp. 266-275). ${ }^{22}$ So, I suspect that the objection above is partly a product of Humean influences in recent philosophy. But putting the historical points aside, I believe the best way to defend the explanatory connection between qualitative properties and their associated powers is to insist that the connection is indeed transparent in many cases, despite the fact that grounding does not involve entailment. Consider, for example, structural properties, which are prominent in both everyday life and in natural science. The roundness of a ball or the tetrahedral structure of silane provide examples. These are paradigmatic examples of non-dispositional properties because they arguably have a geometrical essence rather than a dispositional essence. For this reason some dispositional essentialists, such as Ellis (2002, p. 173), accept that structural properties do not fall under the dispositional essentialist thesis. Yet, it seems clear that the nature of a structural property determines which causal powers are associated with it. ${ }^{23}$ This is not a brute fact. Rather, by reflecting on worldly cases, we can see why certain structural properties confer certain powers rather than others. As Weissman once put it, it is obvious why it is contradictory to think one can 'fill a round hole with a square peg' (1978, p. 292). The geometry of the case constrains the causal possibilities, and Weissman argues that this happens throughout nature. The fact that a key shaped in a certain way can unlock some locks rather than others is not simply a brute fact but rather is explained, in part, by the geometries of the complementary interactions of lock and key (Weissman 1978, p.289). Similar examples can be given in the case of molecular structure. It is not surprising that hydrogen and carbon have the reciprocal powers to produce $\mathrm{CH}_{4}$ rather than $\mathrm{CH}_{5}$. Covalent bonding behaviour is constrained by the number of electrons and free electron spaces in the relevant shells. The formation of $\mathrm{CH}_{4}$ is explained in part by the fact that carbon has four electrons in its outer shell while a hydrogen atom has just one.

In these cases, then, there seems to be no particular mystery about why the structural properties are fit for grounding certain powers rather than others. If one likes talk of meta-grounding, one could simply say that these grounding facts are grounded in the properties themselves (see e.g. Bennett 2011 for details about this meta-grounding strategy). Of course, things are not so straightforward in the case of the fundamental properties of physics, because it seems less likely that we have epistemic access to their qualitative natures, ${ }^{24}$ in which case the relevant explanatory connections will have to

\footnotetext{
22 I am grateful to Can Laurens Loewe and Dominik Perler for drawing my attention to this historical connection (among others). I have also learnt from John Marenbon that, more generally, the notion of necessary-but-non-essential accidents was popular in the medieval period, especially in the work of Porphyry (see the Isagoge, Barnes 2003).

23 Such examples have been discussed by Heil (2003, p. 86), Kimpton-Nye (2018, Ch. 3) and Coates (2020), among others.

24 But even here there is a debate to be had. As a referee has pointed out, if ontic structural realism is correct, then all fundamental properties will be structural in some sense. So, it might yet turn out that the kinds of explanatory examples discussed earlier-where structures ground powers - are pervasive at fundamental
} 
be posited for purely theoretical reasons. This would hardly be surprising, though, given that the properties in question are themselves theoretical, as are the grounding relations that are posited. In any case, my aim here has merely been to respond to the worry that it is a mystery how non-modal entities could ever ground and explain modal entities. I accept that this is an issue that requires more attention than I have been able to give it in this paper, and I welcome further work on it. Nonetheless, I hope to have done enough to motivate the idea that structural properties, which plausibly have a geometrical essence, necessarily constrain a range of powers in a transparent way. Powers, we might say, are necessary consequences of such properties even though they do not constitute those properties. ${ }^{25}$

\section{Necessitarianism with grounding and essential dependence}

Our discussions in the previous two sections show that if we are to hold that properties ground powers, then there are reasons not to say that properties have a powerful essence, on pain of metaphysical incoherence. However, as the work of Fine (2015, pp. 306-307) and others shows, it is perfectly coherent for there to be a relation of essential dependence in the opposite direction, which is to say that a grounded entity might be essentially dependent on that which grounds it. ${ }^{26}$ So, the grounding necessitarian has the option to accept that powers are essentially dependent on the properties that ground them. As we shall now see, this issue turns on the question of whether powers are multiply realizable. But before addressing the issue of multiple realizability, let us introduce the notion of essential dependence in more detail.

To say that $\mathrm{Y}$ essentially depends on $\mathrm{X}$ is to say that $\mathrm{X}$ is part of the essence of $\mathrm{Y}$. In order to begin to know what an entity is, we need to know about the entities upon which it essentially depends. For instance, in order to understand what a certain set is, we need to understand that a set is essentially dependent on the members it contains. If this is correct, then we cannot fully explain what a specific set is without specifying the members that it contains. Given that relations of essential dependence are explanatory in this way, they are plausibly asymmetric in the same way that grounding relations plausibly are. For if they were symmetric, this would leave us with circular metaphysical explanations, which most take to be unacceptable. ${ }^{27}$ For this reason,

Footnote 24 continued

levels. This would require, in the current framework, that the relevant structures are non-modal. I would welcome further work on this form of structural realism.

25 It is tempting to say, on this theory, that powers are the consequential essences of properties. However, in contemporary metaphysics the notion of consequential essence is normally associated with logical consequences rather than metaphysical consequences (see Fine 1995a, p. 57). There might be parallels, though, with the Aristotelian notion of propria, which concerns the accidental but necessary consequences of a natural kind. In the current case, the necessary consequences are those of structural properties rather than natural kinds.

26 Indeed, Fine has suggested that it will always be the case that grounded entities are essentially dependent on their grounds (2015, pp. 306-307). But as we shall see, in the current context such a principle rules out the possibility of the multiple realization of powers, which some necessitarians might wish to accept.

27 Recently, Thompson (2016) and Barnes (2018) have resisted orthodoxy and argued that circular metaphysical explanations are acceptable in some cases (see also Yates 2018). Unfortunately I do not have the space here to discuss their arguments. However, I note that Barnes and Thompson do not argue that all 
Fine (2015, p. 297), Lowe (1998, Ch. 6) and others claim that all relations of ontological dependence are asymmetric. Another orthodox view about essential dependence is that when such a relation holds it does so as a matter of metaphysical necessity. This has to be the case because if the relation were contingent, it would be accidental and thereby contradict the idea that the dependee is part of the essence of the depender. However, as Fine famously argues, it is not plausible that the concept of essence can be reduced to the concept of metaphysical necessity, because there are cases of metaphysical necessitation that are not cases of essence. Indeed, grounding necessities are a case in point: as Fine argues (1994), the existence of Socrates necessitates the existence of the singleton containing Socrates, but it is implausible to think that one needs to appeal to the singleton when specifying the essence of Socrates. ${ }^{28}$

If we accept the grounding version of necessitarianism discussed in the previous section, a certain claim about essential dependence might then seem plausible, which is that it is part of the essence of a power that it is grounded in a certain type of qualitative property rather than some other. For example, one might think it cannot simply be a brute necessary fact that, say, the power to roll is grounded in sphericality rather than some other shape property. Again, a comparison with Fine's infamous case of grounding is useful here, in which Socrates grounds the singleton set containing Socrates. Is it a brute fact that this particular singleton is grounded by Socrates rather than some other entity? Fine's answer is a resounding 'no': '...it should somehow be part of the nature of singleton Socrates that its existence is to be determined in this way from the existence of Socrates' $(2015$, p. 297). Fine argues that this sort of principle generalizes because it is implausible to think that grounding relations are unconstrained by the natures (i.e. essences) of the grounded entities.

So, Finean considerations favour the idea that if the properties of things ground their powers, then powers are essentially dependent on those properties that ground them. On the other hand, if powers are not strictly essentially dependent on those qualitative properties, the theory would be compatible with the multiple realizability of powers, which some theorists might be willing to endorse. This multiple realizability view would still count as a version of necessitarianism, as I have defined it, because properties would necessitate powers (by grounding them), even though there would not be necessitation in the other direction (from the power to the property). However, this denial of essential dependence would push the grounding theorist further away from some of the orthodox versions of necessitarianism discussed in Sect. 2, which typically have to deny the possibility of the multiple realization of powers. For example, if properties and powers are identical, it is clear that the same power cannot be correlated

\section{Footnote 27 continued}

metaphysical explanations are circular. In other words, their proposal is that relations of ontological dependence are non-symmetrical rather than symmetrical. This means that the grounding theory I am proposing is consistent with what Barnes and Thomson say, given that they do not claim that relationships of ontological dependence go in both directions in all cases.

28 Yates (2013, Sect. 4) also argues that there are good reasons for dispositional essentialists to adopt a Finean primitivist conception of essence. Wildman (2013), in contrast, argues in favour of a sophisticated modal conception of essence, and suggests that facts about essence are analysable in terms of metaphysical necessities of a specific kind. I lean towards Fine's view that essential dependence is primitive, but due to space limitations I cannot pursue this debate further here. What is important for our purposes is that relations of essential dependence entail metaphysically necessary connections, even if the reverse is not true. 
with different properties (unless identity is contingent, which Kripkeans typically deny).

I shall not attempt to the settle the question of multiple realizability here given that my main aim is to explore the conceptual landscape of necessitarianism. However, it is worth noting that even if no actual cases of the multiple realization of powers are to be found, this is compatible with there being multiple realization across different nonactual possibilities. For example, if there could be alien qualities that ground certain types of power that we find in our world, this would be enough to sever the connection between grounding and essential dependence in the current context. ${ }^{29}$

\section{Are the grounding theories anti-humean?}

The aim of this section is to situate the grounding theories discussed so far within the debate between Humeans and anti-Humeans. Given that Humean metaphysics is typically characterized by its rejection of necessary metaphysical connections in nature, as expressed by Hume's Dictum, one might naturally assume that the grounding theory of powers is an anti-Humean position. However, as we shall see, this issue is not quite as straightforward as it appears. Moreover, contemporary Humeanism is typically associated with a thesis about properties known as quidditism, and on the grounding theory of powers there is at least one sense in which properties-on which natural modality supervenes-are quidditistic.

As Wilson (2010) explains, the rough formulation of Hume's Dictum is as follows:

'HD: There are no metaphysically necessary connections between distinct, intrinsically typed, entities' (2010, p. 598)

Now, if 'distinct' just means 'non-identical', then it seems clear that the grounding theory of powers violates Hume's Dictum and provides an anti-Humean view. For as we saw earlier, the claim that a certain property grounds a certain power is incompatible with the claim that that property is identical with that power. Hence, properties and powers are numerically distinct on the grounding view. However, as Wilson argues (2010, p. 602), it is implausible to think that the notion of distinctness at work in Hume's Dictum amounts to nothing more than non-identity, for this would leave Humeans with a principle that is implausibly strong. For example, sets are non-identical with their concrete members, but surely no sensible Humean would deny that sets are necessarily constituted by their members. Surely, when Humeans uphold Hume's Dictum, they do not intend to bring such uncontroversial cases of necessity into question. What this suggests, then, is that the notion of distinctness at work in Hume's Dictum must be stronger than mere numerical distinctness.

\footnotetext{
29 There is also another sense in which we might say that powers are multiply realizable (or not). If we opt for a trope theory of qualitative properties, where tropes are particulars, we can ask whether a specific power of an object is essentially dependent on the particular qualitative property (trope) that grounds it. If it is not, then the power is multiply realizable by different tropes. The answer to this question is likely to depend in part on whether tropes are transferable. If indiscernible tropes can be freely swapped around (metaphysically speaking), then it might be quite natural to allow that an object's power could have been grounded in a distinct (indiscernible) quality trope.
} 
In a 2008 paper about Hume's Dictum and its application in the realm of properties, Stoljar considers four possible interpretations of distinctness which are all stronger than the notion of mere numerical distinctness (i.e., non-identity): weak modal distinctness, strong modal distinctness, mereological distinctness and essencedistinctness. We shall not discuss mereological distinctness here because, as Stoljar (2008, pp. 266-267) notes, this notion is typically applied in cases involving material objects rather than properties. Hence, it is not clear that a version of Hume's Dictum based on mereological distinctness could be generalized to properties. This leaves the weak modal, strong modal, and essence-based interpretations. As we shall see, whether or not the grounding theories of powers violate Hume's Dictum depends on which of these notions of distinctness is in play. If Hume's Dictum is formulated in terms of weak modal distinctness, then some grounding theories violate it while others do not. If Hume's Dictum is based on strong modal distinctness, then the grounding theories do not violate Hume's Dictum. Finally, if Hume's Dictum is formulated using an essence-based notion of distinctness, then some grounding theories violate it while others do not.

Let us start with the definitions of these three notions of distinctness as presented by Stoljar (2008, pp. 265-268):

'Weak modal distinctness: $F$ is weakly modally distinct from $G$ if and only if it is possible that $\mathrm{F}$ is instantiated and $\mathrm{G}$ is not $o r$ it is possible that $\mathrm{G}$ is instantiated and F is not' (2008, p. 265)

'Strong modal distinctness: $F$ is strongly modally distinct from $G$ if and only if it is possible that $F$ is instantiated and $G$ is not and it is possible that $G$ is instantiated and F is not' (2008, p. 266)

'Distinctness in essence: $F$ is distinct in essence from $G$ just in case the essence of F is wholly distinct from the essence of G' $(2008$, p. 267)

As the definition above indicates, entities can be weakly modally distinct even if one of the entities in question necessitates the other. That is, if the existence of $F$ necessitates the existence of G, F and $\mathrm{G}$ will still be weakly modally distinct as long as the existence of $\mathrm{G}$ does not necessitate the existence of $\mathrm{F}$. This will be the case if, for example, $\mathrm{G}$ is a multiply realizable state. In contrast, in order for two entities-F and $\mathrm{G}$ - to be strongly modally distinct, there must not be necessitation in either direction, meaning that $\mathrm{F}$ can exist without $\mathrm{G}$ and vice versa. Clearly, then, weak modal distinctness does not entail strong modal distinctness, but strong modal distinctness entails weak modal distinctness.

Using these two notions of distinctness we can now generate two different versions of Hume's Dictum:

$H D(W E A K)$ There are no metaphysically necessary connections between weakly modally distinct, intrinsically typed, entities.

HD (STRONG) There are no metaphysically necessary connections between strongly modally distinct, intrinsically typed, entities.

How then do these versions of Hume's Dictum play out in the case of the grounding theories of powers, discussed in Sects. 3 and 4? The grounding theory accepts that properties necessitate powers (by grounding them), but we saw how there is wriggle room on the question of whether powers are multiply realizable. If a power is essentially 
dependent on a certain property, then the power will not be multiply realizable. The power will necessitate the relevant property as well as vice versa. Importantly, this means that if a grounding theorist accepts that powers are essentially dependent on the properties that ground them, then properties and powers will not be weakly modally distinct. Therefore, such a view will be perfectly consistent with HD (WEAK). If properties and powers are not weakly modally distinct, then they simply do not fall under the scope of HD (WEAK). So, a version of the grounding theory which denies the multiple realizability of powers will be consistent with Humeanism, if by 'Humean' we mean that HD (WEAK) is preserved. In contrast, if a grounding theorist accepts the multiple realizability of powers, then properties and powers will be weakly modally distinct. Properties and powers would then fall under the scope of HD (WEAK), and since the grounding theorist does posit a metaphysically necessary connection from property to power (the necessity of grounding), then HD (WEAK) will be violated. Hence, if a grounding theorist accepts the multiple realizability of powers, the theory will be anti-Humean, if by 'Humean' we mean that HD (WEAK) is preserved.

As Wilson (2010, pp. 602-603) notes, however, it is unlikely that many selfcertifying Humeans would want to commit to HD (WEAK), because like the 'non-identity' version of HD, there seems to be clear counterexamples to it. For example, determinates (like 'is scarlet') and determinables (like 'is red') are weakly modally distinct (since determinables are multiply realizable) and yet it seems overwhelmingly plausible that determinates necessitate the corresponding determinable. Hence, when considering whether the grounding theories are Humean, a more interesting question is whether they violate versions of HD based on strong modal distinctness or essencebased distinctness, since these versions are more likely to be what serious Humeans have in mind. ${ }^{30}$

In the case of HD (STRONG), the status of the grounding theory of powers is clear. The grounding theories discussed in Sects. 3 and 4 do not violate HD (STRONG) because they do not accept that properties and powers are strongly modally distinct. Given that a property grounds a certain power, the power cannot fail to exist if the property does. Hence, properties and powers do not fall under the scope of HD (STRONG). This means that the grounding theories are consistent with Humeanism, if by 'Humean' we mean that HD (STRONG) is preserved.

Finally, let us consider the non-modal version of HD which is based on the notion of essence:

$H D(E S S E N C E)$ There are no metaphysically necessary connections between intrinsically typed entities whose essences are wholly distinct.

As in the case of HD (WEAK), whether or not the grounding theory violates HD (ESSENCE) depends on its stance regarding the essential dependence of powers on properties. As discussed earlier, power types are always individuated, at least in part, by their relational modal profile. However, as we have seen, the grounding theorist has the option to insist that power types are also essentially dependent on the properties that ground them, thereby ruling out the multiple realization of powers. But if that option is taken, it seems that the qualitative properties and the powers they ground

\footnotetext{
30 Wilson also discusses the extent to which the various versions of Hume's Dictum are analytically true. Due to space limitations I will not discuss this issue here, nor will I attempt to answer the question of which version of Hume's Dictum is the most popular one in the Humean literature.
} 
will not have wholly distinct essences, since the power will essentially involve that very quality. The upshot is that if this essential dependence claim is accepted by the grounding theorist, then properties and powers will not be distinct in the way described by HD (ESSENCE). Hence, HD (ESSENCE) would not be violated by properties and powers on that view, since they would not fall under the scope of the principle. Such a view would therefore be consistent with Humeanism, if by 'Humean' we mean that HD (ESSENCE) is preserved.

Unsurprisingly, the outcome is different if the grounding theorist rejects the essential dependence of powers on properties and accepts that powers are multiply realizable. Once we sever the essential dependence of powers on properties, there is then no reason to think that the essences of properties and powers overlap. Properties will have a qualitative quidditistic essence (more on this below) while powers will have a purely modal essence. In that case, HD (ESSENCE) would clearly be violated: properties and powers would have distinct essences but the former would metaphysically necessitate (i.e. ground) the latter. Hence, if a grounding theorist accepts the multiple realizability of powers, then the theory will be anti-Humean, if by 'Humean' we mean that HD (ESSENCE) is preserved.

To round off this section, let us move away from Hume's Dictum and consider other ways in which the grounding theories might (or might not) be considered to be in the general spirit of Humean metaphysics. Contemporary Humeanism is closely associated with the metaphysical principle of Humean Supervenience, as popularized by Lewis (1986). According to this principle, all metaphysical phenomena-including facts of natural modality-supervene on nothing more than 'the spatiotemporal arrangement of local qualities: perfectly natural intrinsic properties' (Lewis 1986, p. ix). Within this framework, the local qualities do not have a dispositional essence but rather a primitive, self-contained identity. Some make this point by saying that properties are quidditistic. ${ }^{31}$

Interestingly, there seems to be much about this Humean Supervenience project that grounding theorists about powers can agree with, even though the latter formulate their positions using the notion of grounding rather than supervenience. We saw earlier how properties are primitive qualities on the grounding theory, albeit qualities that ground powers. One can therefore describe the theory as a version of quidditism. Moreover, given that the grounding theory is a version of strong actualism, its proponents will surely be happy to say that facts of natural modality globally supervene on the worldly arrangement of properties. At first glance, then, the grounding theories seem to be in the spirit of Lewisian Humean Supervenience. There are, however, other ways in which the grounding theories depart from the contemporary Humean project. The most obvious difference is that, unlike Lewisians, the grounding theorists accept a more local grounding or supervenience claim, which is that specific properties fully ground specific powers. ${ }^{32}$ And as we shall now see, grounding theorists might also diverge in some ways from the Lewisian understanding of quidditism.

\footnotetext{
31 Lewis makes the further claim that these properties 'need nothing bigger than a point at which to be instantiated' (Lewis 1986, p. ix). Some critics argue that this stipulation clashes with findings in quantum mechanics but for our purposes we need not discuss this debate.

32 I am grateful to a referee for emphasizing this point.
} 
As Smith (2016, p. 240) points out, Lewis sometimes appears to view quidditism primarily as a principle about the possibility of free recombination/permutation of properties: 'Quidditism is the premise that tells us that the permutation is indeed a different possibility. Two different possibilities can differ just by the permutation of fundamental properties' (Lewis 2009, pp. 209-210). Smith (2016, p. 240) refers to this version of quidditism as 'recombinatorial-quidditism', to convey that it is a modal thesis about how the mosaic of properties can be freely rearranged in other possible worlds. The other version of quidditism, mentioned above, is a thesis about the non-dispositional, primitive identity of properties, which Smith (2016, p. 239) calls 'individuation-quidditism'. Smith observes that recombinatorial-quidditism probably entails individuation quidditism, because if a property were individuated modally, as it is on the dispositional essentialist conception of properties, restrictions would surely be imposed on how properties can be arranged in other possible worlds. But interestingly for our purposes, it is less plausible that individuation-quidditism entails recombinatorial-quidditism (Smith 2016, p. 241). The grounding theories introduced in Sects. 3 and 4 illustrate why. These theories accept individuation-quidditism but it is less clear that a grounding theorist should accept recombinatorial-quidditism. Since properties ground powers, and given that we are assuming grounding necessitarianism, it follows that a property must confer the same power(s) in any world in which it is instantiated. And this fact will surely impose constraints on how properties are arranged in various possible worlds. ${ }^{33}$ What all this shows is that the grounding theories are Humean in the sense that they accept individuation-quidditism, but anti-Humean in the sense that they are likely to reject recombinatorial-quidditism, which is a core feature of the Lewisian Humean project.

To summarize, in response to the question of whether the grounding theories are Humean, the answer is: it depends on what we mean by 'Humean'. The grounding theories accept one version of quidditism but reject another. And some versions of the grounding theory violate some versions of Hume's Dictum, while others do not.

\section{Other options: necessitarianism with grounding in the opposite direction}

In this section and the one to follow, we shall briefly identify further variants of the kinds of necessitarianism covered so far. Until now we have been discussing a theory on which the properties of things are more fundamental than, and the grounds of, the powers of those things. For the purposes of this paper I am assuming the orthodox view that grounding is asymmetric. So, if properties ground powers, it cannot be that powers also ground properties. However, another option for the necessitarian is to deny that properties ground powers and to posit a grounding relation in the opposite direction, which is to say that the powers of things ground the properties of those things. Although I find this grounding claim less plausible than the alternative, there has been a small

${ }^{33}$ It is beyond the scope of this paper to try to settle the question of just how strong those constraints are. As mentioned in footnote 3, dispositionalist anti-Humeans disagree on whether powers necessitate their manifestations. If a grounding theorist accepts that powers do necessitate their causal manifestations, then it seems Hume's Dictum will be violated. I am grateful to Wolfgang Swarz for emphasizing this point. 
number of philosophers who are happy to take natural modal facts to be fundamental. For example, Lange (2009) accepts an ontology of fundamental subjunctives, and if one thinks that powers are closely tied to subjunctives (as, for instance, Bird does) then Lange's subjunctive facts might look a lot like primitive powers. With such a view in play, one could then ground properties in subjunctive facts by, for example, accepting the view developed by Whittle called 'causal nominalism' (Whittle 2009), on which properties are sets of objects that share certain primitive subjunctives in common.

Are there other versions of this approach that have realist rather than nominalist aspirations? I believe there are. Mumford's 'cluster' theory (2004) could be interpreted in this way. According to a proposal explored by Mumford, universals are nothing more than clusters of powers, and one way of spelling this out is to say that properties are mereologically composed of powers (Mumford 2004, p. 171). If one denies that composition is identity, it seems that such a view amounts to a grounding theory: properties are grounded in clusters of fundamental powers.

\section{Other options: necessitarianism with essentialist emergence}

Once we clearly distinguish grounding and essential dependence, other possible versions of necessitarianism present themselves. We can, for example, conceive of cases of essential dependence that do not involve grounding. Some cases of emergence arguably have this feature. ${ }^{34}$ Emergent entities are sometimes defined as fundamental entities that are necessarily ontologically dependent (see e.g. Barnes 2012). On this view, we can think of the concept of fundamentality as more to do with ungroundedness than independence. Plausibly, emergent entities are not grounded in their emergent base: the base does not fully explain the emergent entity and is not sufficient for it. As Barnes puts it, God has to do more than just create an emergent base in order to create an emergent entity (2012, p. 885). Nonetheless, emergent entities are necessarily dependent on other things. And if an emergent entity is not multiply realizable, the ontological dependence in question might well be essential dependence: perhaps it is part of the essence of, say, emergent mental states that they emerge from brains rather than lumps of concrete.

These observations raise the following possibilities: Firstly, perhaps the properties of things emerge from their powers. This would be a case in which properties essentially depend on powers but where the former are not grounded in the latter (or in anything else). Alternatively, the essential dependence could go in the other direction, such that ungrounded powers are essentially dependent on properties. It is unclear whether either of these views has ever been held but perhaps Shoemaker's 1998 position could be interpreted as the view on which properties essentially depend on powers but are not grounded in them. Shoemaker seems to be a dispositional essentialist about properties but also suggests in later work that properties are 'categorical bases' (1998, p. 65). This could be interpreted as the claim that property instantiations are ungrounded categorical states which are essentially dependent on powers. Some critics have struggled to make sense of Shoemaker's 1998 position (e.g. Armstrong

\footnotetext{
34 I am grateful to José Tomas Alvarado for discussion of this issue.
} 
2004, p. 139; Mumford 2008) and a speculative diagnosis of their puzzlement could be that these commentators have not noticed that this position is an emergentism of sorts.

\section{Formalizing the new necessitarianisms}

Now that we have introduced a variety of versions of necessitarianism, we are in a position to formalize the differences between them and represent the possibilities using the table at the end of this section. According to Kit Fine, facts about grounding and essential dependence reveal how things are constituted. Hence, to say that Socrates' singleton is essentially dependent on Socrates is to say that Socrates is an essential constituent of that set (see e.g. Fine 1995b, p. 275). More recently, Fine (2015) also speaks of grounding in terms of constitution, as a way of providing unified foundations for essence and ground. Hence, grounding entities are said to be constitutively sufficient for that which they ground, while in cases of essential dependence the dependee is constitutively necessary for the depender.

After capturing grounding and essence in these terms, Fine introduces two sentential connectives to express them. First, essential dependence, or constitutive necessity, is represented by a right-to-left arrow (Fine 2015, p. 299):

$$
\varphi \leftarrow \psi
$$

This formula indicates that $\psi$ is essentially dependent on $\varphi$, or that $\varphi$ is constitutively necessary for $\psi$. Grounding (constitutive sufficiency) is then represented by a left-toright arrow (Fine 2015, p. 302):

$$
\varphi \rightarrow \psi
$$

This formula indicates that $\varphi$ (fully) grounds $\psi$, or that $\varphi$ is constitutively sufficient for $\psi$. Finally, where we have a case of both grounding and essential dependence (i.e., where one state of affairs is constitutively necessary and sufficient for another), Fine uses a double-headed arrow:

$$
\varphi \leftrightarrow \psi
$$

This formula says both that $\varphi$ grounds $\psi$ and also that $\psi$ is essentially dependent on $\varphi$. Or, to put it more elegantly, $\varphi$ is constitutively necessary and sufficient for $\psi$. If what was said earlier is correct, then we have a correct instance of (3) if $\varphi$ expresses the existence of Socrates and $\psi$ expresses the existence of Socrates' singleton set.

One way of stating the grounding theory of powers that we started with in Sect. 3, then, is to use Fine's terminology and say that the (qualitative) properties of things are constitutively sufficient for their powers. If one takes the further step of denying the possibility of the multiple realization of powers, as discussed in Sect. 4, then one can say that the properties of a thing are both constitutively necessary and sufficient for its powers. Let us call this the 'strong' grounding theory of powers, since it accepts that 
powers necessitate properties as well as vice versa. I shall not go as far as to say that Fine's framework provides the only way of fleshing out the varieties of necessitarianism that we have discussed, but as we shall see below, making use of Fine's concepts is useful in several ways. For example, it brings out in a clear way the similarities and differences between the widely held identity theory of properties (discussed in Sect. 2) and this 'strong' grounding theory of powers.

Returning to formula (3) above, the strong grounding theory of powers would say that a true instance of (3) can be obtained by replacing $\varphi$ with a proposition that ascribes a certain property (quality) or properties to an object, and replacing $\psi$ with a proposition about a certain power (or powers) that the object has. Let us formalise the property ascription as 'Px' and the power ascription as 'Dx' (I choose the letter ' $\mathrm{D}$ ' since I am using the terms 'power' and 'disposition' interchangeably). Px would therefore represent a property ascription such as ' $\mathrm{x}$ is charged', while Dx would represent a power ascription such as ' $x$ has the power to repel'. 35 The strong grounding theory of powers can then be characterized by the following formula:

$$
\mathrm{Px} \leftrightarrow \mathrm{Dx}
$$

If we accept that properties ground powers but powers are not essentially dependent on properties (thereby allowing the possibility of the multiple realization of powers), we are left with formula (5):

$$
(\mathrm{Px} \rightarrow \mathrm{Dx}) \wedge \neg(\mathrm{Px} \leftarrow \mathrm{Dx})
$$

However, some care is needed when formalizing the theories in this way. The metaphysical notions of constitutive necessity and sufficiency have very different characteristics to the purely logical notions of necessity and sufficiency. Hence it must be emphasized that in (2) and (3) above the connectives are not the material conditional and biconditional respectively. The language here is not that of classical logic. As well as the fact that the connectives above express metaphysically necessary connections, another important difference is that the classical logical notions of necessary conditions and sufficient conditions are converses of one another. So, for instance, if one can say that being Socrates is sufficient for being a man, then one can equally say that being a man is necessary for being Socrates. In contrast, it is not plausible to think that constitutive necessary conditions and constitutive sufficient conditions are converses of one another in this way. If they were converses, then if it were true that $\varphi$ grounds $\psi$ (i.e., that $\varphi$ is constitutively sufficient for $\psi$ ), it would follow that $\varphi$ is essentially dependent on $\psi$ (i.e., that $\psi$ is constitutively necessary for $\varphi$ ). However, as we saw earlier, it is very difficult to think of a case of grounding in which this metaphysical structure obtains. Certainly, in the Finean example discussed earlier, of singleton Socrates, it would be odd to say both that Socrates grounds singleton Socrates and that Socrates is essentially dependent on singleton Socrates.

\footnotetext{
35 Again, I shall not commit here on what kind of modal fact is expressed by a power ascription. If the Birdian approach is taken, then Dx will be equivalent to a subjunctive, such as ' $\mathrm{x}$ would repel a similarly charged particle if it were in close proximity'.
} 
There is another important difference between constitutive necessary and sufficient conditions (essence and ground), and the necessary and sufficient conditions of classical logic. As we saw earlier, the orthodox view is that relationships of grounding and essential dependence are asymmetric, which stems from the fact that such relationships are determinative and explanatory (though in different senses). This implies that statements of constitutive necessary and sufficient conditions ( ' $\varphi \leftrightarrow \psi^{\prime}$ ') carry an asymmetry that we do not find in statements of biconditional equivalence. Where ' $\leftrightarrow$ ' is interpreted as the classical truth-functional connective, there will be a symmetry such that if $\varphi \leftrightarrow \psi$ is the case, then $\psi \leftrightarrow \varphi$ is the case. This is not so in the case of constitutive necessary and sufficient conditions. Under the current framework, if the qualitative properties of things are constitutively necessary and sufficient for their powers, we cannot then say that the powers of a thing are constitutively necessary and sufficient for the qualitative properties of the thing. This is ruled out because, as highlighted earlier, we are assuming it is metaphysically incoherent to say that qualitative properties ground powers and vice versa, or that qualitative properties essentially depend on powers and vice versa.

One reason why the previous paragraph is important is that it reveals the sense in which the 'strong' grounding theory of powers, expressed in (4) above, is distinct from the powerful qualities 'identity' theory discussed in Sect. 2. If qualitative properties are identical with powers, then of course powers are identical with qualitative properties. In contrast, if the qualitative properties of a thing are constitutively necessary and sufficient for its powers, then it is not the case that its powers are constitutively necessary and sufficient for its qualitative properties. Putting the point in another way, qualitative properties are ontologically prior to powers on the strong grounding theory of powers, whereas on the identity theory qualities and powers are on a metaphysical par. It is important to emphasize, though, that the 'strong' grounding theory of powers carries the same modal consequences as the identity theory. Since relations of grounding and essential dependence hold necessarily if they hold at all, then it follows on the 'strong' grounding theory of powers that the qualitative properties of things necessitate they that have certain kinds of power and also that the powers of things necessitate that they have certain qualitative properties. Importantly, then, this strong grounding theory is not a radical departure from some of the versions of necessitarianism discussed in Sect. 2. Given that the powerful quality theorists' identity claim is difficult to sustain, for reasons given earlier, the 'strong' grounding theory of powers is one that proponents of the powerful qualities theory should find attractive. Indeed, Heil himself seems to unwittingly lean in the direction of a grounding theory of powers when he says that 'things do what they do because they are as they are' (Heil 2012, p. 80). ${ }^{36}$ I think the grounding approach captures this kind of explanation much better than Heil's own identity theory. For if properties are identical with powers, it's difficult to see how properties can explain powers.

\footnotetext{
36 In a recent paper, Coates (2020) also articulates the powerful qualities theory in terms of grounding and argues that this allows the powerful qualities theorists to distinguish themselves from pure powers theorists (contra Taylor 2018). Coates's article was published online when this paper was in the final stages of publication and I am not able to give it the attention it deserves. I shall merely note that Coates's theory appears to have much in common with what I have called the 'strong' grounding theory of powers.
} 


\begin{tabular}{|c|c|c|c|c|c|c|c|}
\hline & $\mathrm{Px} \rightarrow \mathrm{Dx}$ & $\mathrm{Dx} \leftarrow \mathrm{Px}$ & $\mathrm{Dx} \rightarrow \mathrm{Px}$ & $\mathrm{Px} \leftarrow \mathrm{Dx}$ & $\begin{array}{l}\text { Allows the } \\
\text { multiple } \\
\text { realization } \\
\text { of } \\
\text { powers? }\end{array}$ & $\begin{array}{l}\text { Properties } \\
\text { necessitate } \\
\text { the powers? }\end{array}$ & $\begin{array}{l}\text { Powers } \\
\text { necessitate } \\
\text { the } \\
\text { properties? }\end{array}$ \\
\hline $\begin{array}{l}\text { The grounding theory } \\
\text { of powers (without } \\
\text { essential dependence). }\end{array}$ & $\checkmark$ & $x$ & $x$ & $x$ & $\checkmark$ & $\checkmark$ & $x$ \\
\hline $\begin{array}{l}\text { Standard dispositional } \\
\text { essentialism (arguably } \\
\text { incoherent). }\end{array}$ & $\checkmark$ & $\checkmark$ & $x$ & $x$ & $\checkmark$ & $\checkmark$ & $x$ \\
\hline $\begin{array}{l}\text { The strong grounding } \\
\text { theory of powers. }\end{array}$ & $\checkmark$ & $x$ & $x$ & $\checkmark$ & $x$ & $\checkmark$ & $\checkmark$ \\
\hline $\begin{array}{l}\text { Properties essentially } \\
\text { emerge from powers. }\end{array}$ & $x$ & $\sqrt{ }$ & $x$ & $x$ & $\checkmark$ & $\checkmark$ & $x$ \\
\hline $\begin{array}{l}\text { The grounding theory } \\
\text { of properties (with } \\
\text { essential dependence } \\
\text { of properties on } \\
\text { powers). }\end{array}$ & $x$ & $\checkmark$ & $\checkmark$ & $x$ & $x$ & $\checkmark$ & $\checkmark$ \\
\hline $\begin{array}{l}\text { The grounding theory } \\
\text { of properties (without } \\
\text { essential dependence). }\end{array}$ & $x$ & $x$ & $\sqrt{ }$ & $x$ & $x$ & $x$ & $\checkmark$ \\
\hline $\begin{array}{l}\text { Powers both ground } \\
\text { properties and are } \\
\text { essentially dependent } \\
\text { on them (arguably } \\
\text { incoherent). }\end{array}$ & $x$ & $x$ & $\sqrt{ }$ & $\sqrt{ }$ & $x$ & $x$ & $\checkmark$ \\
\hline $\begin{array}{lr}\text { Powers } & \text { essentially } \\
\text { emerge } & \text { from } \\
\text { properties. } & \\
\end{array}$ & $x$ & $x$ & $x$ & $\checkmark$ & $x$ & $x$ & $\checkmark$ \\
\hline
\end{tabular}

Fig. 1 The conceptual space of necessitarianism using grounding and essential dependence

With Fine's formalizations of constitutive sufficiency (grounding) and constitutive necessity (essential dependence) in play, we can now present the new spectrum of necessitarian theories based on the framework of grounding and essential depen- 
dence. It should be noted again that relations of grounding and essential dependence are taken to be asymmetric. However, if symmetric grounding or symmetric essential dependence are coherent notions, as Barnes (2018) and Thompson (2016) have recently argued, then the table could be expanded to include cases in which properties and powers necessarily mutually ground or depend on each other. In that case I would welcome further discussion of those other theories too. Regarding notation, recall that 'Px' represents qualitative property predication, such as ' $\mathrm{x}$ has mass', while 'Dx' represents power predication, such as ' $x$ has the power to gravitationally attract'. These predicates should be read in as flexible a way as possible so that, for example, they could be shorthand for conjunctions of properties or powers. This is because, again, a grounding theorist about powers might allow that a single property grounds multiple powers, in which case 'Dx' may be read as shorthand for a conjunction of powers (which will in turn represent a complex modal fact). Please note also that, as explained above, the arrows in the formulas do not represent connectives in classical truth-functional logic, but rather the metaphysical notions of ground and essential dependence. Finally, as noted in the first column of the table, rows 3 and 8 are arguably incoherent for reasons discussed in Sect. 2. This leaves 6 coherent forms of necessitarianism in the table (Fig. 1).

\section{Conclusions}

The dominant forms of necessitarianism anchor claims about metaphysically necessary connections in nature in the idea that properties are identical with, or essentially dependent on, powers. These necessitarian theories face problems that are familiar in the recent literature and I believe it is time to explore new forms of necessitarianism. The concepts of metaphysical grounding and essential dependence open up space for doing just that. In this paper I have explored this conceptual space in detail and compared the resultant versions of necessitarianism with existing literature on properties and powers. My hope is that this will provide a platform for important work on a new necessitarian research programme. This, in turn, will influence a range of discussions in ontology and theories of modality.

Acknowledgements First, I would like to thank two anonymous referees for excellent comments that helped to improve the paper. I am also grateful to José Tomas Alvarado, Paul Audi, Lorenzo Azzano, Steve Barker, Alexander Bird, Ralf Busse, Alex Carruth, Giacomo Giannini, Joaquim Giannotti, Julie Godfrey, Yang Guo, Siegfried Jaag, Sam Kimpton-Nye, Can Laurens Loewe, John Marenbon, Stephen Mumford, Ben Page, Dominik Perler, Andrea Raimondi, Gonzalo Rodriguez-Pereyra, Markus Schrenk, Erica Shumener, Ben Smart, Mack Sullivan, Jamie Taylor, Henry Taylor, Barbara Vetter, Lisa Vogt, Michael Wallner, David Westland, Nathan Wildman, Neil Williams and Ruoyu Zhang. Earlier versions of this paper were presented at the Workshop on Philosophical Methodology, University of Barcelona (March 2019), the New Foundations of Dispositionalism Conference, University of Exeter (April 2019), and the Departmental Philosophy Seminar at the Pontifical Catholic University of Chile, Santiago (August 2019). I am very grateful to the organizers and audiences at those events and especially grateful to José Tomas Alvarado for funding my research visit to Santiago under project 1160001 (Fondecyt, Chile). Finally I would like to thank Barbara Vetter, Dominik Perler, and members of their Human Abilities reading group for giving me very helpful feedback on the paper. Human Abilities is a Centre for Advanced Studies in the Humanities (Kollegforschungsgruppe) funded by the Deutsche Forschungsgemeinschaft (DFG). 
Open Access This article is licensed under a Creative Commons Attribution 4.0 International License, which permits use, sharing, adaptation, distribution and reproduction in any medium or format, as long as you give appropriate credit to the original author(s) and the source, provide a link to the Creative Commons licence, and indicate if changes were made. The images or other third party material in this article are included in the article's Creative Commons licence, unless indicated otherwise in a credit line to the material. If material is not included in the article's Creative Commons licence and your intended use is not permitted by statutory regulation or exceeds the permitted use, you will need to obtain permission directly from the copyright holder. To view a copy of this licence, visit http://creativecommons.org/licenses/by/4.0/.

\section{References}

Alvarado, J. T. (Forthcoming). A metaphysics of platonic universals and their instantiations. Shadow of universals. New York: Springer.

Armstrong, D. M. (1973). Belief, truth and knowledge. Cambridge: Cambridge University Press.

Armstrong, D. M. (1983). What is a law of nature?. Cambridge: Cambridge University Press.

Armstrong, D. M. (1997). A world of states of affairs. Cambridge: Cambridge University Press.

Armstrong, D. M. (2004). Truth and truthmakers. Cambridge: Cambridge University Press.

Armstrong, D. M. (2005). Four disputes about properties. Synthese, 144, 309-320.

Audi, P. (2012a). Grounding: Toward a theory of the in-virtue-of relation. Journal of Philosophy, 109, $685-711$.

Audi, P. (2012b). A clarification and defense of the notion of grounding. In F. Correia \& B. Schnieder (Eds.), Metaphysical grounding: Understanding the structure of reality (pp. 101-121). Cambridge: Cambridge University Press.

Audi, P. (2019). Why truthmaking is not a case of grounding. Philosophy and Phenomenological Research. https://www.onlinelibrary.wiley.com/doi/10.1111/phpr.12605.

Azzano, L. (2019). The question of realism for powers. Synthese, 196, 329-354.

Barker, S. (2013). The emperor's new metaphysics of powers. Mind, 122, 605-653.

Barnes, J. (2003). Porphyry introduction. Oxford: Oxford University Press. (translated with commentary by J. Barnes).

Barnes, E. (2012). Emergence and fundamentality. Mind, 121, 873-901.

Barnes, E. (2018). Symmetric dependence. In R. Bliss \& G. Priest (Eds.), Reality and its structures: Essays in fundamentality (pp. 50-69). Oxford: Oxford University Press.

Bennett, K. (2011). By our bootstraps. Philosophical Perspectives, 25, $27-41$.

Bennett, K. (2017). Making things up. Oxford: Oxford University Press.

Bird, A. (2007). Nature's metaphysics: Laws and properties. Oxford: Oxford University Press.

Black, R. (2000). Against quidditism. Australasian Journal of Philosophy, 78, 87-104.

Carruth, A. (2016). Powerful qualities, zombies and inconceivability. The Philosophical Quarterly, 66, 25-46.

Cartwright, N. (1989). Nature's capacities and their measurement. Oxford: Oxford University Press.

Chakravartty, A. (2007). A metaphysics for scientific realism: Knowing the unobservable. Cambridge: Cambridge University Press.

Coates, A. (2020). Making sense of powerful qualities. Synthese. https://doi.org/10.1007/s11229-020-025 76-5.

Contessa, G. (2019). Powerful qualities or pure powers? Metaphysica, 20, 5-33.

Correia, F., \& Schnieder, B. (2012). Grounding: An opinionated introduction. In F. Correia \& B. Schnieder (Eds.), Metaphysical grounding: Understanding the structure of reality (pp. 1-36). Cambridge: Cambridge University Press.

Dasgupta, S. (2014). On the plurality of grounds. Philosophers' Imprint, 14, 1-28.

deRosset, L. (2010). Getting priority straight. Philosophical Studies, 149, 73-97.

Dumsday, T. (2013). Using natural-kind essentialism to defend dispositionalism. Erkenntnis, 78, 869-880. Ellis, B. (2001). Scientific essentialism. Cambridge: Cambridge University Press.

Ellis, B. (2002). The philosophy of nature: A guide to the new essentialism. Montreal: McGill-Queen's University Press.

Ellis, B., \& Lierse, C. (1994). Dispositional essentialism. Australasian Journal of Philosophy, 72, $27-44$. 
Engelhard, K. (2010). Categories and the ontology of powers: A vindication of the identity theory of powers. In A. Marmodoro (Ed.), The metaphysics of powers: Their grounding and their manifestations (pp. 41-57). Abingdon: Routledge.

Fales, E. (1990). Causation and universals. London: Routledge.

Fine, K. (1994). Essence and modality. In J. Tomberlin (Ed.), Philosophical Perspectives 8: Logic and Language (pp. 1-16). Atascadero: Ridgeview.

Fine, K. (1995a). Senses of essence. In W. Sinnott-Armstrong (Ed.), Modality, morality and belief. Essays in honor of Ruth Barcan Marcus (pp. 53-73). Cambridge: Cambridge University Press.

Fine, K. (1995b). Ontological dependence. Proceedings of the Aristotelian Society, 95, 269-290.

Fine, K. (2015). Unified foundations for essence and ground. Journal of the American Philosophical Association, 1, 296-311.

Garcia, R. K. (2015). Two ways to particularize a property. Journal of the American Philosophical Association, 1, 635-652.

Giannotti, J. (2019). The identity theory of powers revised. Erkenntnis. https://doi.org/10.1007/s10670-01 9-00122-5.

Harré, R., \& Madden, E. (1975). Causal powers: A theory of natural necessity. Oxford: Blackwell.

Heil, J. (2003). From an ontological point of view. Oxford: Oxford University Press.

Heil, J. (2012). The universe as we find it. Oxford: Oxford University Press.

Hildebrand, T. (2016). Two types of quidditism. Australasian Journal of Philosophy, 94, 516-532.

Ingthorrson, R. (2013). Properties: Qualities, powers, or both? dialectica, 67, 55-80.

Jaag, S. (2014). Dispositional essentialism and the grounding of natural modality. Philosophers' Imprint, 14. http://hdl.handle.net/2027/spo.3521354.0014.034.

Jacobs, J. (2011). Powerful qualities, not pure powers. The Monist, 94, 81-102.

Jaworski, W. (2016). Structure and the metaphysics of mind. New York: Oxford University Press.

Kimpton-Nye, S. (2018). Common ground for laws and metaphysical modality. Ph.D. Thesis, King's College London.

Kistler, M. (2002). The causal criterion of reality and the necessity of laws of nature. Metaphysica, 3, 57-86.

Kripke, S. (1980). Naming and necessity. Cambridge: Harvard University Press.

Lange, M. (2009). Laws and lawmakers: Science, metaphysics, and the laws of nature. Oxford: Oxford University Press.

Lewis, D. (1986). On the plurality of worlds. Oxford: Blackwell.

Lewis, D. (1997). Finkish dispositions. Philosophical Quarterly, 47, 143-158.

Lewis, D. (2009). Ramseyan humility. In D. Braddon-Mitchell \& R. Nola (Eds.), Conceptual analysis and philosophical naturalism (pp. 203-222). Cambridge MA.: MIT Press.

Locke, D. (2012). Quidditism without quiddities. Philosophical Studies, 160, 345-363.

Lowe, E. J. (1998). The possibility of metaphysics. Oxford: Oxford University Press.

Lowe, E. J. (2010). On the individuation of powers. In A. Marmodoro (Ed.), The metaphysics of powers: Their grounding and their manifestations (pp. 8-26). Abingdon: Routledge.

Marmodoro, A. (2017). Aristotelian powers at work: Reciprocity without symmetry in causation. In J. Jacobs (Ed.), Causal powers (pp. 57-76). Oxford: Oxford University Press.

Martin, C. B. (2008). The mind in nature. Oxford: Oxford University Press.

Maxwell, N. (1968). Can there be necessary connections between successive events? The British Journal for the Philosophy of Science, 19, 1-25.

McKitrick, J. (2003). A case for extrinsic dispositions. Australasian Journal of Philosophy, 81, $155-174$.

McKitrick, J. (2018). Dispositional pluralism. Oxford: Oxford University Press.

Molnar, G. (2003). Powers: A study in metaphysics. Oxford: Oxford University Press. (Ed. S. Mumford).

Mumford, S. (1998). Dispositions. Oxford: Oxford University Press.

Mumford, S. (2004). Laws in nature. London: Routledge.

Mumford, S. (2008). Powers, dispositions, properties or a causal realist manifesto. In R. Groff (Ed.), Revitalizing causality: Realism about causality in philosophy and social science (pp. 139-151). Abingdon: Routledge.

Mumford, S., \& Anjum, R. L. (2011). Getting causes from powers. Oxford: Oxford University Press.

Oderberg, D. (2017). Finality revived: Powers and intentionality. Synthese, 194, 2387-2425.

Prior, E., Pargetter, R., \& Jackson, F. (1982). Three theses about dispositions. American Philosophical Quarterly, 19, 251-257.

Psillos, S. (2006). What do powers do when they are not manifested? Philosophy and Phenomenological Research, 72, 137-156. 
Rodriguez-Pereyra, G. (2005). Why truthmakers. In H. Beebee \& J. Dodd (Eds.), Truthmakers: The contemporary debate (pp. 17-32). Oxford: Oxford University Press.

Rodriguez-Pereyra, G. (2015). Grounding is not a strict order. Journal of the American Philosophical Association, 1, 517-534.

Rosen, G. (2010). Metaphysical dependence: Grounding and reduction. In R. Hale \& A. Hoffman (Eds.), Modality: Metaphysics, logic, and epistemology (pp. 109-136). Oxford: Oxford University Press.

Schaffer, J. (2008). Truth and fundamentality: On Merricks's Truth and Ontology. Philosophical Books, 49, $302-316$.

Schaffer, J. (2009). On what grounds what. In D. Manley, D. J. Chalmers, \& R. Wasserman (Eds.), Metametaphysics: New essays on the foundations of ontology (pp. 347-383). New York: Oxford University Press.

Schaffer, J. (2017). The ground between the gaps. Philosophers' Imprint, 17. http://hdl.handle.net/2027/ spo.3521354.0017.011.

Schrenk, M. (2010). The powerlessness of necessity. Noûs, 44, 725-739.

Schroer, R. (2010). Is there more than one categorical property? The Philosophical Quarterly, 60, 831-850.

Shoemaker, S. (1980). Causality and properties. In P. van Inwagen (Ed.), Time and cause: Essays presented to Richard Taylor (pp. 109-135). Dordrecht: Reidel.

Shoemaker, S. (1998). Causation and metaphysical necessity. Pacific Philosophical Quarterly, 79, 59-77.

Skiles, A. (2015). Against grounding necessitarianism. Erkenntnis, 80, 717-751.

Smith, D. (2016). Quid quidditism est? Erkenntnis, 81, 237-257.

Stoljar, D. (2008). Distinctions in distinction. In J. Kallestrup \& J. Hohwy (Eds.), Being reduced: New essays on reduction, explanation, and causation (pp. 263-279). New York: Oxford University Press.

Strawson, G. (2008). The identity of the categorical and dispositional. Analysis, 68, 271-282.

Swoyer, C. (1982). The nature of natural law. Australasian Journal of Philosophy, 60, 203-223.

Taylor, J. H. (2013). In defence of powerful qualities. Metaphysica, 14, 93-107.

Taylor, H. (2018). Powerful qualities and pure powers. Philosophical Studies, 185, 1423-1440.

Thompson, N. (2016). Metaphysical interdependence. In M. Jago (Ed.), Reality Making (pp. 38-56). Oxford: Oxford University Press.

Trogdon, K. (2013). Grounding: Necessary or contingent? Pacific Philosophical Quarterly, 94, 465-485.

Tugby, M. (2012). Rescuing dispositionalism from the ultimate problem: Reply to Barker and Smart. Analysis, 72, 723-730.

Tugby, M. (2013). Platonic dispositionalism. Mind, 122, 451-480.

Vetter, B. (2011). Recent work: Modality without possible worlds. Analysis, 71, 742-754.

Vetter, B. (2014). Dispositions without conditionals. Mind, 123, 129-156.

Vetter, B. (2015). Potentiality: From dispositions to modality. Oxford: Oxford University Press.

Weissman, D. (1978). Dispositions as geometrical-structural properties. Review of Metaphysics, 32, 275-297.

Whittle, A. (2008). A functionalist theory of properties. Philosophy and Phenomenological Research, 77, 59-82.

Whittle, A. (2009). Causal nominalism. In T. Handfield (Ed.), Dispositions and causes (pp. 242-285). Oxford: Oxford University Press.

Wildman, N. (2013). Modality, sparsity, and essence. The Philosophical Quarterly, 63, 760-782.

Williams, N. E. (2019). The powers metaphysic. Oxford: Oxford University Press.

Wilson, A. (2013). Schaffer on laws of nature. Philosophical Studies, 164, 653-667.

Wilson, J. (2010). What is Hume's Dictum, and why believe it? Philosophy and Phenomenological Research, $80,595-637$.

Wilson, J. (2014). No work for a theory of grounding. Inquiry, 57, 535-579.

Wippel, J. F. (2000). The metaphysical thought of Thomas Aquinas. Washington, D.C.: The Catholic University of America Press.

Yates, D. (2013). The essence of dispositional essentialism. Philosophy and Phenomenological Research, 87, 93-128.

Yates, D. (2018). Inverse functionalism and the individuation of powers. Synthese, 195, 4525-4550.

Publisher's Note Springer Nature remains neutral with regard to jurisdictional claims in published maps and institutional affiliations. 